\title{
Pelestarian Aspek Kesemestaan Dan Kesetempatan Dalam Arsitektur Bangsal Sitihinggil Di Kraton Yogyakarta
}

\author{
Alwin Suryono \\ Prodi Arsitektur/Fakultas Teknik, Universitas Katolik Parahyangan \\ alwin@unpar.ac.id
}

\begin{abstract}
ABSTRAK
Bangsal Sitihinggil Kraton Yogyakarta, terbangun lengkap tahun 1926, bergaya campuran arsitektur Tradisional Jawa-Eropa. Semula sebagai tempat penobatan Sultan-sultan Mataram dan Presiden pertama Republik Indonesia, kini untuk upacara resmi kerajaan dan objek wisata. Tujuan studi ini mengungkap aspek kesemestaan-kesetempatan arsitektur bangsal Sitihinggil, dan mendeskripsikan konsep pelestariannya. Metoda studi adalah deskriptif-eksplanatif, dengan pendekatan Budaya Jawa-Arsitektur-Pelestarian. Aspek kesemestaan berdasar filosofi Budaya Jawa "kesatuan interaksi alam-sosial-spiritual", aspek kesetempatan berupa "filosofi toleransi" dan gaya arsitektur tradisional Jawa. Relasi alam terkait tata ruang simetri terhadap sumbu Filosofis dan bangunan adaptif lingkungan. Relasi sosial terkait dialog antara Sultan (di dalam bangsal) dengan rakyat (duduk di Alun-Alun Utara). Relasi spiritual terkait ritual Sultan bermeditasi di bangsal ini dan memandang ke arah Tugu Pal Putih. Wujud filosofi "toleransi" melalui 2 gaya arsitektur dalam satu bangunan. Konsep pelestarian: Preservasi tata ruang (posisiketerbukaan bangsal); Restorasi Alun-alun Utara (rumput dan pohon sekeliling dilebatkan); Preservasi-perawatan rutin bangunan (atap, plafon, balok tumpangsari, talang, jendela, tiang, ornamen).
\end{abstract}

Kata kunci: kesemestaan, kesetempatan, budaya, preservasi

\section{ABSTRACT}

The Sitihinggil Kraton Yogyakarta building, completed in 1926, has a EuropeanJavanese architecture style. It is originally a coronation place of the Mataram Sultans and the first Indonesia President. In the present time, it is used for royal official ceremonies and tourist attractions. The purpose of this study is to reveal the universallocal aspects of Sitihinggil architecture and describe its conservation concept. The method used is descriptive-explanatory, with the approach of Javanese CultureArchitecture-Conservation. The universal aspect is based on the Javanese culture philosophy "unitary natural-social-spiritual interaction", whereas the local aspects are "philosophy of tolerance" and architecture style. Natural relation associates with symmetrical space layout towards the philosophical axis and the adaptive building (to the environment). The social relation associates with the dialogue between the Sultan (inside the building) with the people (sitting in the North Square). The spiritual relation associates with the Sultan's meditation ritual in this building while looking at the White Post's direction. "Tolerance" philosophy could be seen through the architectural styles. Conservation concept: Preservation of space layout (opennessposition of the building); Restoration of the North Square (thickened the surrounding grass and trees); Preservation-routine maintenance of building (Roofs, ceilings, beams, gutters, windows, pillars, ornaments)

Keywords: Keywords: universal, local, culture, preservation. 


\section{Pendahuluan}

Negara Kesatuan Republik Indonesia memiliki puluhan daerah dan suku bangsa yang masing-masing memiliki budaya khas, termasuk arsitektur tradisionalnya. Salah satu yang terkenal adalah arsitektur Tradisional Jawa di Yogyakarta, dengan keunikan terkait budaya dan alam lokalnya. Sosoknya dapat dilihat pada arsitektur istana, rumah tradisional dan tempat ibadah. Banyak arsitektur tradisional Jawa di Yogyakarta telah dijadikan bangunan cagar budaya, terutama yang ada di Kraton Yogyakarta. Keindahan/ keunikan bangunan-bangunan tradisional Kraton telah lama menjadi daya tarik wisata dunia, dan perannya saat ini adalah sebagai objek wisata disamping peran asalnya.

Peran ganda dari bangunan-bangunan tradisional di Kraton Yogyakarta berdampak pada keutuhan-keaslian bangunan asalnya. Umumnya keutuhan/keaslianya masih terjaga, namun ada juga yang kurang terjaga. Sebagai objek wisata dituntut untuk memiliki daya tarik, kenyamanan/keamanan maksimal bagi wisatawan, dan efektifefisien bagi pengelola. Disisi lain, sebagai bangunan cagar budaya berusia tua dituntut untuk terjaga keutuhan-keasliannya semaksimal mungkin, agar nilai-nilai asal yang dimiliki dapat bertahan.

Bangunan cagar budaya merupakan kekayaan budaya bangsa, sebagai wujud pemikiran dan perilaku kehidupan manusia, yang penting artinya bagi pemahaman dan pengembangan sejarah, ilmu pengetahuan dan kebudayaan dalam kehidupan bermasyarakat, berbangsa dan bernegara. Karena itu perlu dilestarikan dengan tepat [UURI no.11 tahun 2010].

Bangunan cagar budaya di Kraton Yogyakarta (usia diatas 80 tahun) berdasar pada filosofi Budaya Jawa tentang keberlanjutan, yaitu keseimbangan relasi pada alam, sosial dan spiritual. Filosofi budaya ini bersifat semesta/universal, namun wujud arsitekturnya bersifat setempat (hanya ada di Kraton Yogyakarta). Kesemestaan suatu budaya (arsitektur) menjadikannya condong diapresiasi karena adanya kesamaan dengan tempat-tempat lain, sedangkan kesetempatannya merupakan keunikan yang dapat menjadi daya tarik yang berbeda dengan tempat-tempat lain. Karena itulah aspek kesemestaan dan kesetempatan dalam arsitektur Tradisional Jawa di Kraton Yogyakarta perlu diangkat dan dipermasalahkan dalam studi ini.

Pelestarian dipahami sebagai suatu proses memahami, melindungi, merawat dan melakukan tindakan pelestarian pada suatu tempat (bangunan/lingkungan) bersejarah yang masih ada, agar Nilai-nilainya bertahan [Suryono 2015]. Bangunan bernilai sejarah/budaya bagi Kraton Yogyakarta (tempat penobatan Sultan-sultan kerajaan Mataram dan Presiden RI. pertama, upacara-upacara kerajaan, ritual spiritual Sultan) adalah Bangsal Sitihinggil, yang terletak di bagian muka Kraton. Bangsal ini merupakan wujud arsitektur aspek kesemestaan dan kesetempatan Budaya Jawa. Pemahaman aspek kesemestaan dan kesetempatan dari budaya/arsitektur Bangsal Sitihinggil merupakan hal penting, terkait tekanan globalisasi pada saat ini. Maka isu utama yang dikemukakan adalah pelestarian aspek kesemestaan dan kesetempatan dalam arsitektur Tradisional Jawa dari Bangsal Sitihinggil di Kraton Yogyakarta.

Permasalahan yang diangkat dalam studi ini adalah Apa wujud kesemestaan dan kesetempatan dalam arsitektur dari bangsal Sitihinggil di Kraton Yogyakarta?; Apakah elemen-elemen arsitektur signifikannya?; dan Bagaimana konsep pelestariannya?. Tujuan studi ini adalah mengungkap aspek kesemestaan dan kesetempatan arsitektur Bangsal Sitihinggil dan mendeskripsikan konsep pelestariannya, dengan pendekatan Budaya Jawa, arsitektur dan pelestarian.

Manfaat dari studi ini adalah memberikan pemahaman aspek kesemestaan dan kesetempatan arsitektur, sebagai faktor penting dalam pelestarian arsitektur bangunan 
cagar budaya. Pemahaman tersebut sebagai pengarah proses pelestarian kearah yang tepat, agar nilai-nilai budayanya dapat terjaga sekaligus menjawab tuntutan global. Studi ini juga bermanfaat untuk arstektur masa kini, sebagai masukan untuk tetap berakar pada kelokalan (budaya, alam) namun dapat memenuhi keuniversalan masa kini.

\section{Bahan dan Metode}

Studi pelestarian kesemestaan dan kesetempatan arsitektur Bangsal Sitihinggil Kraton Yogyakarta melalui pendekatan Budaya Jawa, teori arsitektur (aspek bentuk, fungsi, makna), dan teori pelestarian.

\section{Pendekatan Budaya Jawa}

Kebudayaan mempunyai minimal 3 wujud, yaitu [1] sebagai filosofi, nilai-nilai, aturan (wujud ideal); [2] sebagai aktivitas kelakuan berpola dalam masyarakat (sistem sosial); dan [3] sebagai benda-benda hasil karya manusia (kebudayaan fisik) [Koentjaraningrat 2015]. Ke-3 wujud tersebut tidak terpisah satu dengan yang lain.

Filosofi dalam Budaya Jawa yang digunakan dalam studi ini adalah Kaidah Dasar Kehidupan Masyarakat Jawa (kerukunan, toleransi) [Suseno 1988, Endraswara 2010] dan Pandangan Dunia Jawa (kesatuan menyeluruh interaksi spiritual-sosial-alam) [Suseno 1988]. Kata rukun berarti "tenang dan tenteram", tercapai keseimbangan sosial [Suseno 1988]. Toleransi menjadi pokok sikap mental orang Jawa. Toleransi budaya menghendaki bahwa perbedaan-perbedaan budaya hakikatnya adalah satu. Kehadiran budaya lain dianggap sebagai sebuah kekayaan budaya. Orang Jawa dapat menerima dan hidup bersama bangsa lain dengan mesra, tanpa mengunggulkan diri [Endraswara 2010].

Dalam Pandangan Dunia Jawa, realitas dilihat sebagai satu kesatuan menyeluruh dan saling berhubungan, tidak dibagi dalam berbagai bidang yang terpisah-pisah. Interaksi-interakasi sosial sekaligus merupakan sikap terhadap alam, dan sikap spiritual [Suseno 1988].

\section{Teori Arsitektur}

Pendekatan arsitektur dari studi ini melalui teori Capon, yang melihat arsitektur sebagai susunan dari elemen-elemennya aspek bentuk-fungsi-makna [Capon 1999]. Aspek bentuk berupa bangunan dan ruang luar, aspek fungsi mengacu pada kegiatan yang diwadahi, dan aspek makna berupa arti interpretasi dari sosok bangunan dan ruang luar [Suryono 2015]. Kesemestaan dan kesetempatan arsitektur dapat dilihat sebagai aspek makna, yaitu makna dari aspek bentuk arsitektur (bangunan dan ruang luar).

Makna suatu bangunan diperoleh melalui interpretasi seni/sejarah, dan makna simbolik bangunan dapat berupa: Simbolik pemilik/organisasi; Simbolik budaya/gaya hidup; dan Simbolik untuk tujuan tertentu [Capon 1999]. Aspek makna pada studi ini berdasar filosofi Budaya Jawa, dari aspek kesemestaan dan kesetempatan.

Aspek Fungsi dipahami sebagai peran bangunan untuk memenuhi tujuan yang telah ditetapkan, meliputi fungsi fisik, fungsi sosial, fungsi simbol budaya [Capon 1999; Schulz 1997]. Fungsi fisik ialah peran bangunan menyediakan kenyamanan fisik untuk aktifitas yang diwadahi, antara lain [Mangunwijaya 1981; Olgay 1992]: Kenyamanan ruang (luas/bentuk ruang terhadap kebutuhan aktivitasnya); Kenyamanan termal; Kenyamanan visual; dan Kenyamanan audial. Aspek fungsi studi ini mengacu pada kegiatan Kraton masa lalu dan masa kini. 


\section{Teori Pelestarian}

Bangunan bersejarah merupakan perwujudan fisik sejarah masyarakat, bukti material dari cara hidup/ budaya masa lalu, serta sumber material-budaya terbatas yang jika rusak akan tak dapat dikembalikan lagi. Pelestarian peninggalan bangunan bersejarah merupakan sarana signifikan bagi masyarakat agar dapat mempertahankan dan menunjukkan kepribadian dan keunikannya terhadap penyeragaman arsitektur global yang sulit dihindari [Orbasli 2008]. Karena itulah warisan bangunan bersejarah menjadi penting mengingat gencarnya kegiatan modernisasi dan globalisasi kota-kota di dunia yang bila tidak dikendalikan akan memberikan wajah kota yang sama disetiap kota [Antariksa 2007].

Makna suatu bangunan/tempat bersejarah (dari aspek arsitektur atau budaya) adalah nilai yang paling menentukan, yang jika hilang akan menurunkan makna kulturalnya. Makna kultural tersusun dan didukung oleh sejumlah nilai, seperti nilai arsitektural, nilai budaya, nilai sejarah, nilai lansekap, nilai kegunaan. Nilai-nilai tersebut merupakan ciri/sifat khas suatu warisan budaya, yang spesifik terhadap tempat, pengguna dan waktu [Orbasli 2008]. Peran pelestarian adalah mempertahankan nilainilai tersebut, atau bahkan meningkatkannya jika mungkin [Orbasli 2008; Feilden 2003].

\section{Metode}

Studi ini bertujuan mengungkap kesemestaan dan kesetempatan arsitektur Bangsal Sitihinggil di Kraton Yogyakarta dengan cara deskriptif (termasuk Penelitian Kualitatif [Moleong 2010]). Kesemestaan berupa filosofi Budaya Jawa (bersifat universal) dan kesetempatan berupa wujud arsitekturnya dan filosofi Jawa bersifat lokal. Langkah-langkahnya adalah sebagai berikut:

Kesemestaan diungkap berdasar filosofi Budaya Jawa (Pandangan Dunia Jawa) yaitu "kesatuan interaksi pada alam-sosial-spiritual", yang dibaca melalui tata ruang dan selubung dalam dari bangsal Sitihinggil. Kesetempatan diungkap berdasar filosofi Budaya Jawa (Kaidah Dasar Kehidupan Masyarakat Jawa) yaitu "kerukunan, toleransi", yang dibaca melalui sosok arsitektur Bangsal Sitihinggil (gaya arsitektur, struktur bangunan, ornamen-dekorasi).

Elemen-elemen arsitektur signifikan (untuk dilestarikan) dari aspek kesemestaan ialah elemen-elemen tata ruang dan selubung dalam dari bangsal Sitihinggil; dari aspek kesetempatan adalah elemen-elemen dari gaya arsitektur, struktur bangunan dan ornament/dekorasi. Tindakan pelestarian pada elemen-elemen arsitektur signifikan tersebut dideskripsikan berdasar kondisi fisik saat pengamatan, dengan memperhatikan kebutuhan terkait nilai-nilai masa lalu-masa kini dan etika/pedoman pelestarian.

\section{Kasus Studi}

Tata ruang Kraton Yogyakarta mengikuti Sumbu Filosofis Kraton arah Tugu Pal Putih-Kraton-Panggung Krapyak dan sumbu arah Sungai Code-Sungai Winanga (TimurBarat) berdasar filosofi Budaya Jawa [Heryanto 2015] (Gambar 1). Bangsal Sitihinggil terletak pada area muka Kraton Yogyakarta (Gambar 1).

Kasus studi Bangsal Sitihinggil dipilih dari bangunan-bangunan peninggalan Kraton Yogyakarta, dengan metode 'sampel bertujuan' (purposive sampling) melalui pendekatan: Budaya Jawa (peran sosial-spiritual Sultan/Kraton, posisi pada sumbu Filosofis di area muka Kraton); Arsitektur (gaya campuran arsitektur tradisional Jawagaya Eropa); dan pertimbangan Pelestarian (bangunan relatif utuh-asli) (Gambar 1). 


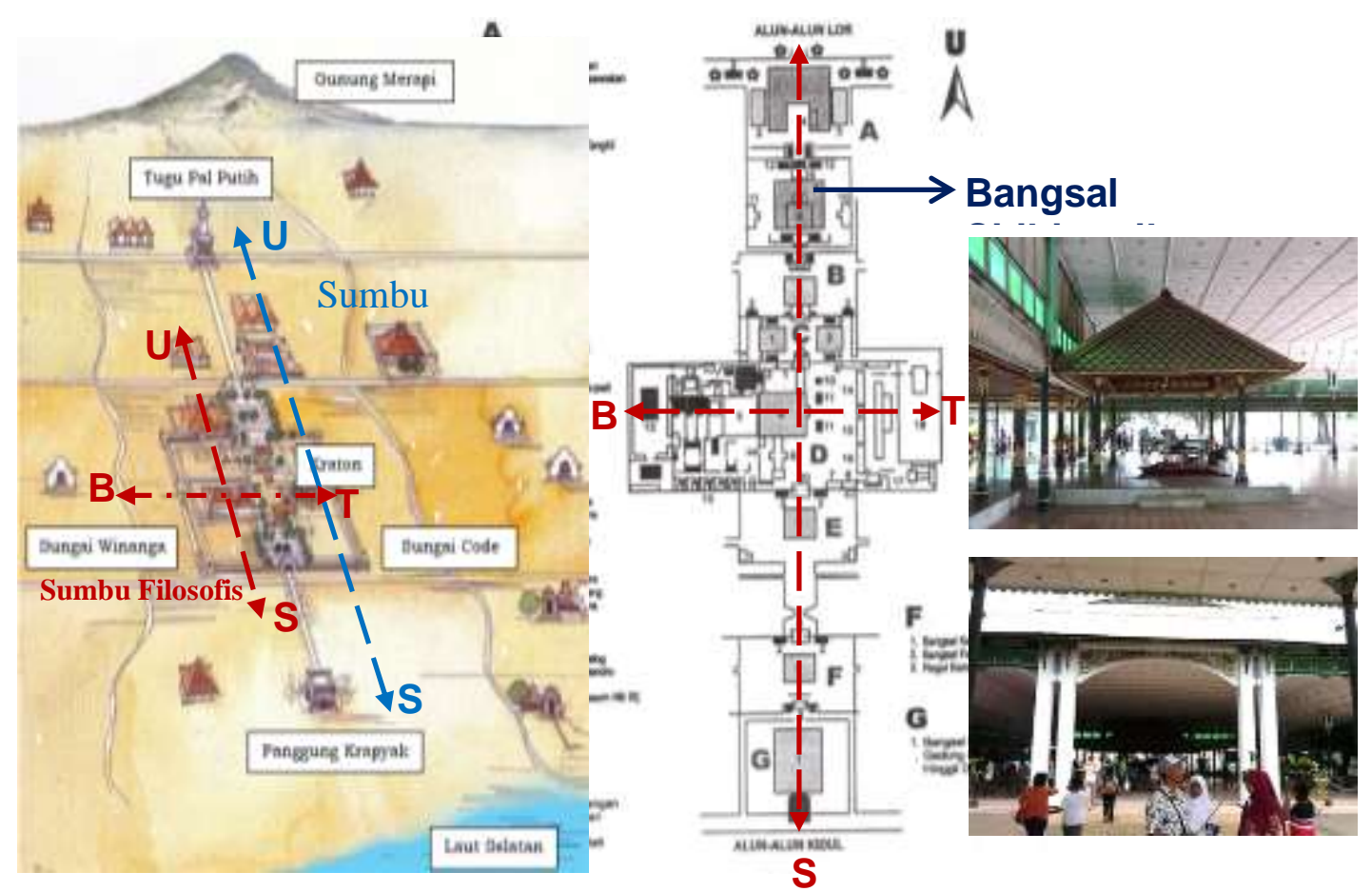

Gambar 1. Kraton - Sumbu Filosofis dan Sumbu Imajiner

Kiri: Gambar situasi Kraton, Sumbu Filosofis dan Sumbu Imajiner. Tengah: Tata masa Kraton Yogyakarta dan Sumbu Filosofis-sumbu Timur-Barat. Kanan-bawah: Fasad muka-tengah. Kanan-atas: Selubung dalam (arsitektur campuran)

(Sumber: https://jogjakini.wordpress.com)

\section{Hasil dan Diskusi}

Hasil studi disusun berdasar aspek kesemestaan (tata ruang dan selubung dalam bangunan) dan aspek kesetempatan (gaya arsitektur, struktur bangunan, dan ornamentasi).

\section{Aspek Kesemestaan Bangsal Sitihinggil}

Aspek Kesemestaan Bangsal Sitihinggil berdasar filosofi Budaya Jawa "kesatuan relasi sosial-spiritual-alam" [Suseno 1988, Endraswara 2010], yang merupakan paduan dari relasi sosial, relasi spiritual dan relasi alam dari arsitektur bangsal Sitihinggil (pada tata ruang dan selubung dalam). Relasi alam terkait tata ruang yang simetri terhadap sumbu Filosofis dan bangunan yang diadaptasikan pada alam lokal (peneranganventilasi alami untuk seluruh ruang dalam) (Gambar 2). Relasi sosial terkait dapat terjadi dialog antara Sultan di dalam bangsal Manguntur Tangkil/Sitihinggil dengan rakyaknya yang duduk di Alun-Alun Utara (Gambar 1). Relasi spiritual terkait kebiasaan Sultan melaksanakan meditasi di Bangsal Manguntur Tangkil, dengan memandang ke arah Tugu Pal Putih [Heryanto 2015] (Gambar 1).

Tata ruang bangsal Sitihinggil (Gambar 2) sebagai berikut:

Area bangsal Sitihinggil lebih tinggi 2 meter-an dari area-area lainnya dalam Kraton, sehingga dari sini dapat memandang ke arah Utara (Alun-alun Utara, jalan Malioboro, Tugu Pal Putih) dan ke arah Selatan (area bangsal Srimanganti-Trajumas, area bangsal Kencana) di dalam Kraton (Gambar 2). Bangsal Manguntur Tangkil ada di dalam bangsal Sitihinggil sisi Selatan, ke duanya menempel ke bangsal Witono. Tata ruang ke tiga bangsal dan ruang-ruang pengapitnya semua simetris kiri-kanan terhadap Sumbu Folosofis. 

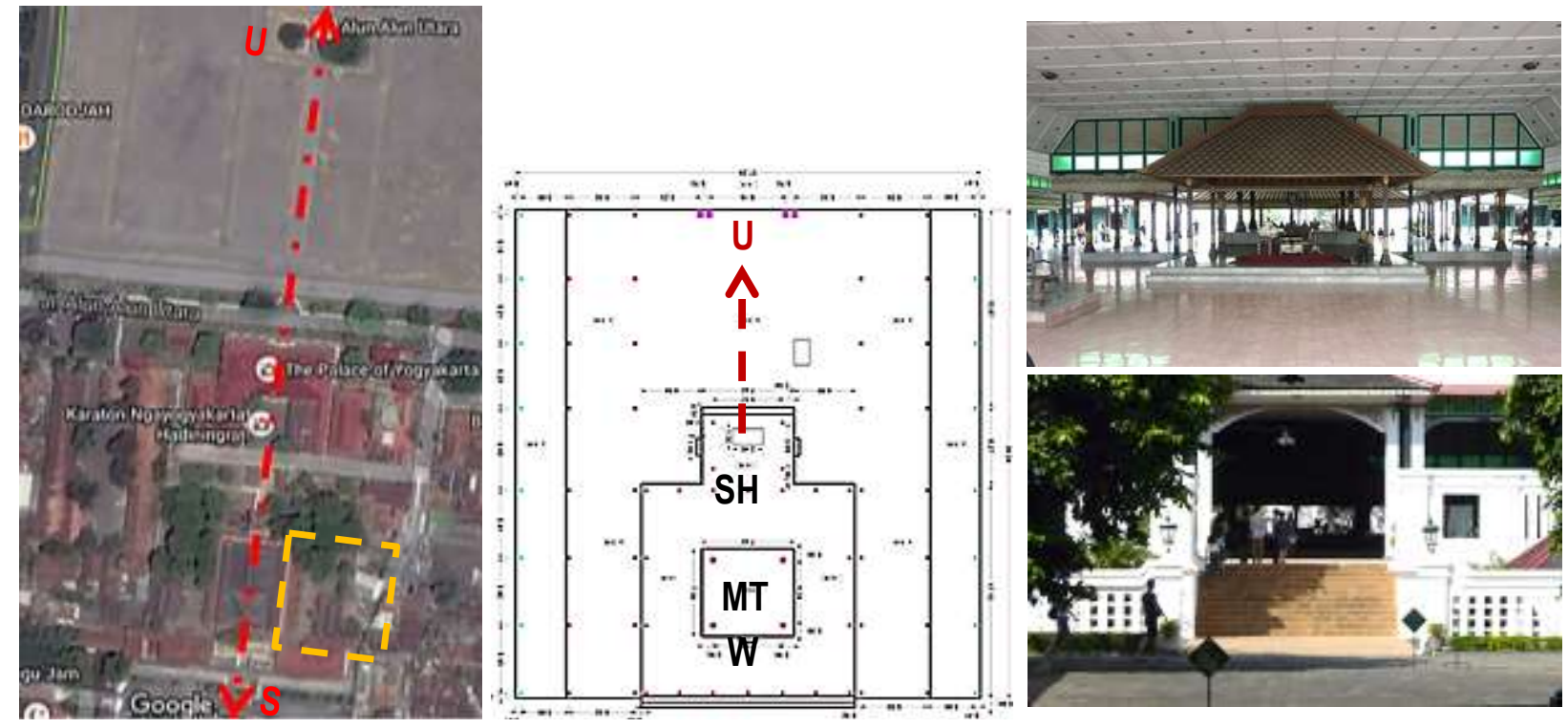

Gambar 2 Tata-ruang Bangsal Sitihinggil

Kiri: Tatanan masa bagian Utara Kraton (bangsal Sitihinggil, bangsal Pagelaran, Alunalun Utara). Tengah: Tata ruang bangsal Sitihinggil (Sh: Sitihinggil, MT: Manguntur Tangkil, W: Witono). Kanan-bawah: Entrance bangsal Sitihinggil (terbuka ke arah Alunalun Utara). Kanan-atas: Ruang dalam bangsal Sitihinggil dan sisi muka bangsal Manguntur Tangkil

Selubung dalam (Gambar 3) memperlihatkan keterbukaan dan paduan dua gaya arsitektur (Tradisional Jawa - Eropa).
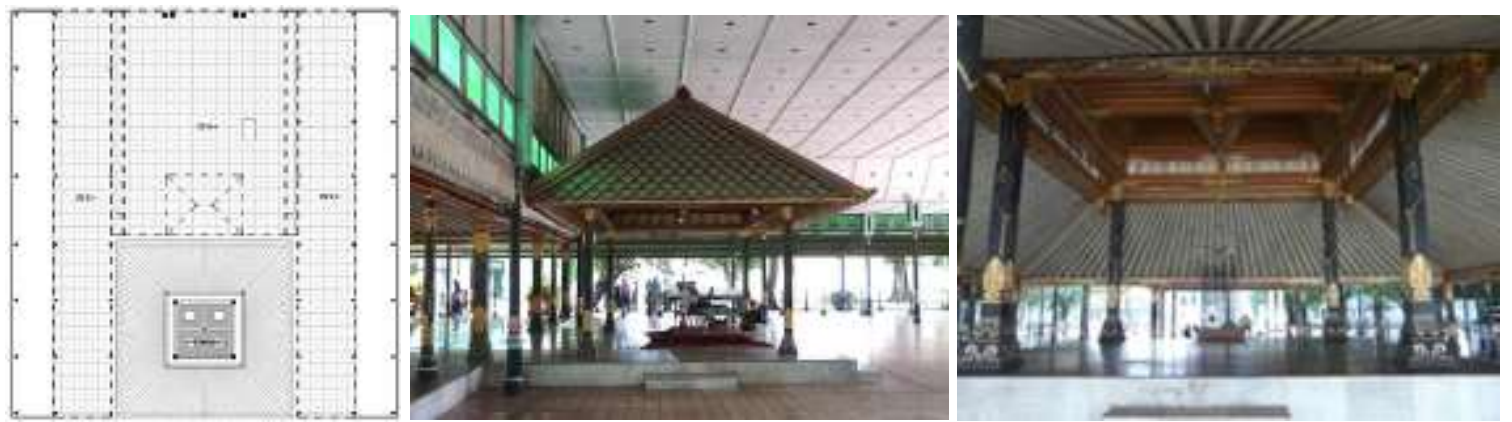

Gambar 3. Selubung Dalam Bangsal Sitihinggil-Witono

Kiri: Gambar Plafon bangsal Sitihinggil dan bangsal Witono. Tengah: Bangsal Manguntur Tangkil didalam bangsal Sitihinggil dan menempel ke bangsal Witono. Kanan: Selubung dalam bangsal Witono

Keterbukaan selubung menghasilkan penerangan alami dan ventilasi alami yang baik, sebagai bentuk relasi arsitektural pada alam sekitar. Pertemuan atap-plafon dari bangsal Sitihinggil-bangsal Witono-ruang-ruang tepi Timur-Barat berupa talang horisontal dan jendela-jendela kaca. Buangan air hujan mengalir lancar (dan tidak bocor), ruang dalam dapat terang dengan ventilasi alami yang baik (prinsip relasi dengan alam lokal).

\section{Aspek Kesetempatan Bangsal Sitihinggil}

Aspek kesetempatan bangsal Sitihinggil berdasar filosofi Budaya Jawa "toleransi" (pada Budaya Eropa) dapat dibaca melalui paduan gaya arsitektur dan ornamentasi, kesetempatan lainnya dapat dibaca melalui gaya arsitektur tradisional Jawa dan 
struktur bangunan. Bangsal Sitihinggil bergaya arsitektur Eropa, bangsal Witono dan Manguntur Tangkil bergaya arsitektur Tradisional Jawa (Gambar 3). Gabungan 2 gaya arsitektur dalam satu bangunan merupakan bentuk toleransi arsitektural Budaya Jawa terhadap Budaya Eropa, sebagai unsur pengaya Budaya Jawa.

Struktur bangunan bangsal Sitihinggil adalah rangka baja (dengan tiang-tiang beton pada entrance); struktur bangsal Witono dan bangsal Mangunkur Tangkil berupa rangka kaku kayu - ring balok tumpang sari; struktur bangunan tepi-tepi adalah rangka baja (tiang bundar). Struktur tiap bangunan berperilaku independen terhadap lainnya (aman untuk gaya gempa bumi), dapat dimaknai sebagai toleransi antar tiap bangunan (toleransi budaya Jawa).
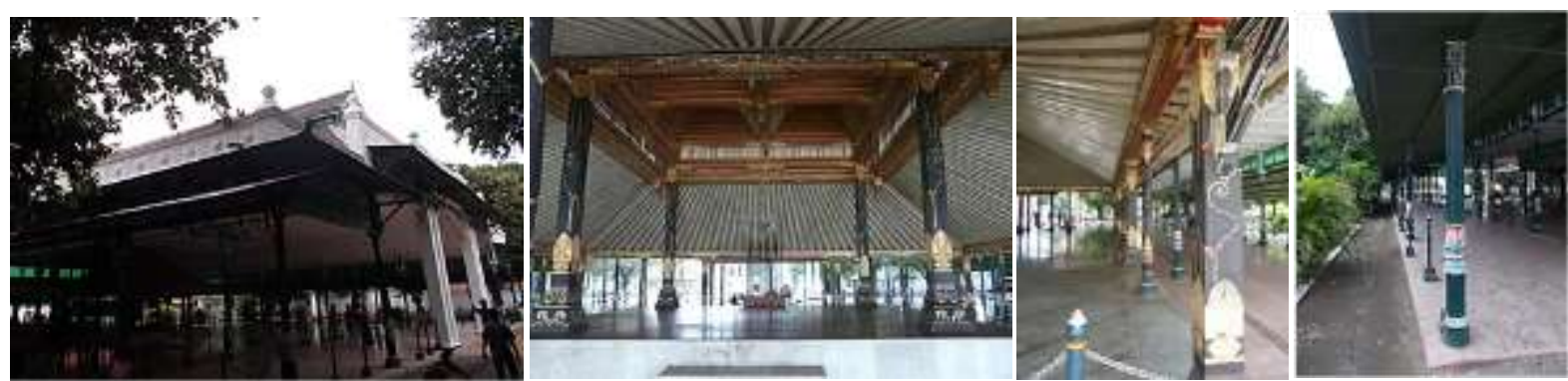

Gambar 4. Struktur Bangunan Bangsal Sitihinggil

Kiri: Struktur bangsal Sitihinggil (tiang beton di tengah, tiang baja bagian tepi). Tengah: Tiang-tiang utama bangsal Witono (rangka kayu, tumpang sari). Kanan-1: Tiang-tiang tepi bangsal Witono (kayu dan besi cor). Kanan-2: Tiang-tiang tepi selasar Timur dan Barat (besi cor bundar)

Ornamen-dekorasi bangsal Sitihinggil terdapat pada atap, tiang, balok dan plafon. Ornamen pada atap berupa ukiran di tepi-puncak wuwung, bagian bawah list-plank, dekoratif wajah raksasa "Kemamang" (penolak bala). Pada tiang-balok beton pada bagian entrance berupa dekorasi gambar naga pola floral. Pada plafon bag=ngsal Sitihinggil berupa dekorasi bintang segi delapan warna emas, plafon bangsal Witono berupa ukiran warna emas di balok-balok tumpang sari dan ornamen nanas. Pada tiang kayu-kotak bangsal Witono berupa ukiran warna emas pada posisi atas-tengah-bawah dan alas umpak. Pada tiang besi-bundar berupa ornamen ukiran bunga tulip warna merah-putih (Gambar 4).

\section{Elemen-elemen Arsitektur Signifikan Dilestarikan}

Elemen-elemen arsitektur signifikan adalah pembentuk makna kesemestaan (tata ruang, selubung dalam) dan makna kesetempatan (gaya arsitektur, ornamen, struktur bangunan) dari bangsal Sitihinggil. Elemen signifikan dari tata ruang bangsal Sitihinggil meliputi: posisi bangsal lebih tinggi dari area lainnya, simetri di tengah pada sumbu Filosofis dan keterbukaan ke arah Alun-alun Utara (Gambar 5). Elemen selubung dalam: keterbukaan selubung (berupa tiang-tiang), talang lebar pada pertemuan tiap plafon/atap bangsal, jendela-jendela kaca atas. 


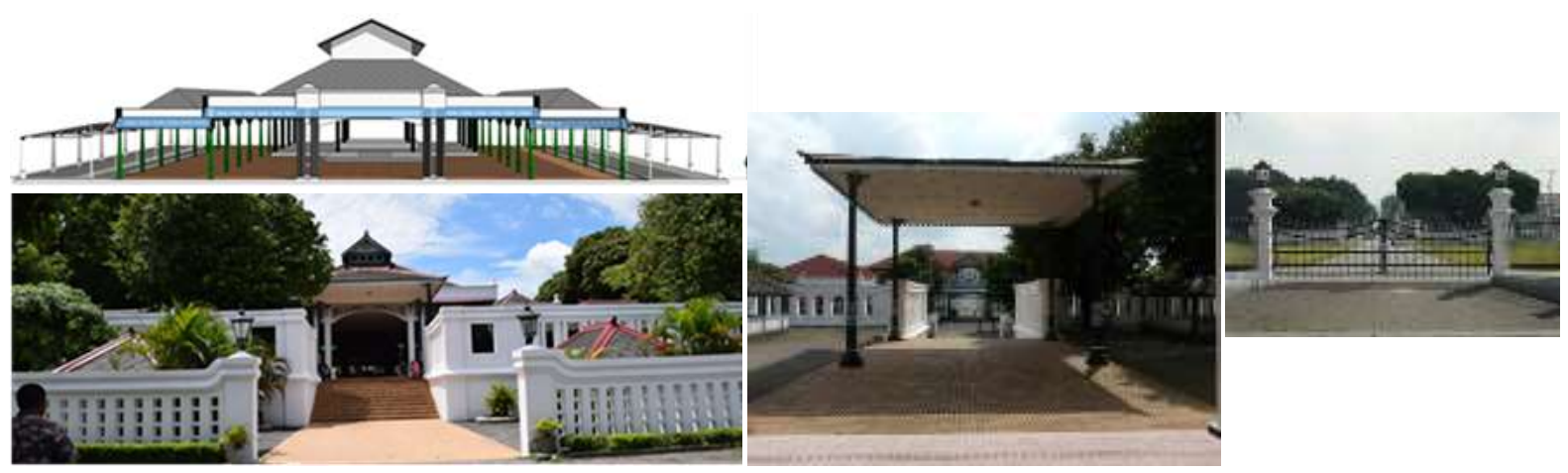

Gambar 5. Elemen Arsitektur Tata Ruang Bangsal Sitihinggil

Kiri-bawah: Pagar dan entrance bangsal Sitihinggil. Kiri-atas: Selubung terbuka. Tengah:

Pandangan ke Alun-alun dari Bangsal Sitihinggil. Kanan: Gerbang Utara Kraton dan

Alun-alun Utara

Elemen signifikan dari gaya arsitektur bangsal Sitihinggil berupa dua gaya arsitektur dalam satu bangunan, yaitu gaya arsitektur Eropa pada bangsal Sitihinggil dan gaya arsitektur Tradisional Jawa pada bangsal Witono-Manguntur Tangkil (Gambar 3), yang dimaknai sebagai toleransi Budaya Jawa.

Elemen signifikan struktur bangsal Sitihinggil ialah rangka baja (tiang-balok) dengan tiang-tiang beton pada bagian entrance; struktur bangsal Witono dan bangsal Mangunkur Tangkil berupa rangka kaku kayu - ring balok tumpang sari, dan struktur bangunan tepi-tepi adalah rangka baja (tiang bundar). Struktur tiap bangunan berperilaku independen (aman jika terjadi gempa bumi), dimaknai toleransi antar tiap bangunan.

Elemen arsitektur signifikan dari ornamen-dekorasi adalah: Pada atap berupa ukiran puncak-tepi wuwung, 'Kemamang", ukiran list-plank; Pada tiang-balok beton berupa bagian entrance (dekorasi gambar naga pola floral); Pada plafon bangsal Sitihinggil berupa dekorasi bintang segi delapan warna emas, plafon bangsal Witono berupa ukiran warna emas dari balok-balok tumpang sari dan ornamen nanas. Pada tiang kayu-kotak bangsal Witono (ukiran warna emas pada posisi atas-tengah-bawah dan alas/umpak), pada tiang besi-bundar (ornamen ukiran bunga tulip warna merahputih).

\section{Konsep Tindakan Pelestarian}

Konsep tindakan pelestarian ditujukan pada elemen-elemen arsitektur signifikan pembentuk makna kesemestaan (tata ruang, selubung dalam) dan makna kesetempatan (gaya arsitektur, ornamen, struktur bangunan) dari bangsal Sitihinggil.

Konsep pelestarian tata ruang adalah Preservasi (mempertahankan yang ada), yaitu posisi bangsal lebih tinggi dari area lainnya, tetap pada sumbu Filosofis secara simetri, dan terbuka ke arah Alun-alun Utara. Alun-alun Utara sebaiknya direstorasi, yaitu diperlebat rumputnya dan ditanami pohon beringin di sekelilingnya. Fasilitas publik ini dapat menjadi lebih asri-sehat, menyejukkan lingkungan untuk masyarakat dan Sultan yang sedang semadi memandang Alun-alun dan Tugu Pal Putih (memperkuat relasi alam dan spiritual). 
Konsep pelestarian selubung dalam adalah Preservasi dan perawatan rutin pada plafon, balok-balok tumpangsari, talang-talang, jendela skylight, tiang-tiang, lantai. Perawatan rutin berikut perbaikan seperlunya.

Konsep pelestarian gaya arsitektur adalah preservasi, yaitu mempertahankan tampilan dua macam gaya arsitektur yang ada, untuk menjaga makna toleransi Budaya Jawa (terhadap Budaya Eropa). Preservasi gaya arsitektur harus disertai dengan tindakan perawatan rutin pada seluruh elemen gaya arsitektur, mulai dari alas tiang sampai elemen balok-balok dan ornamen/dekorasi tumpang sari.

Konsep pelestarian struktur bangunan adalah preservasi dan perawatan rutin terhadap seluruh elemen struktur (balok-balok tumpang sari, tiang-tiang, usuk-usuk atap, elemen-elemen sambungan (purus-lubang, elemen penggantung balok) agar perilaku strukturnya tetap seperti semula. pengeroposan balok/tiang kayu harus diantisipasi terkati bangunan berusia tua.harus memasukkan hasil dan catatan diskusi.

\section{Simpulan}

Simpulan pelestarian aspek kesemestaan dan aspek kesetempatan pada arsitektur bangsa Sitihinggil sebagai berikut:

Aspek Kesemestaan Bangsal Sitihinggil berdasar filosofi Budaya Jawa "kesatuan relasi sosial-spiritual-alam" melalui tata ruang (simetri sumbu Filosofis, adaptif lingkungan) dan selubung dalam (terbuka, bebas pandang ke Alun-alun dan Tugu Pal Putih). Aspek kesetempatan berdasar filosofi "toleransi" Budaya Jawa (pada Budaya Eropa) melalui gaya arsitektur (paduan arsitektur Tradisional Jawa-Eropa), struktur bangunan (independen) dan ornamen-dekorasi.

Elemen-elemen arsitektur signifikan aspek kesemestaan (tata ruang, selubung dalam) dan kesetempatan (gaya arsitektur, struktur bangunan, ornamen-dekorasi) sebagai berikut: Tata ruang berupa posisi bangsal tertinggi di Kraton, simetri pada sumbu Filosofis dan terbuka ke arah Alun-alun Utara. Selubung terbuka, talang pada pertemuan tiap atap bangsal, jendela-jendela kaca atas. Gaya arsitektur paduan harmonis dari arsitektur Eropa dan arsitektur Tradisional Jawa. Struktur bangunan independen antar bagian-bagian bangsal Sitihinggil-Witono-Mangunkur Tangkil (aman terhadap gempa bumi, toleransi Budaya Jawa). Ornamen-dekorasi pada atap (ukiran puncak-tepi wuwung, 'Kemamang", ukiran list-plank); pada tiang-balok beton entrance (dekorasi gambar naga); pada plafon bangsal Sitihinggil (dekorasi bintang segi delapan warna emas), plafon bangsal Witono (ukiran warna emas pada balok-balok tumpang sari dan ornamen nanas, ukiran warna emas pada tiang-tiang dan alas/umpak), dan pada tiang besi bangunan tepi (ornamen ukiran bunga tulip warna merah-putih).

Konsep tindakan pelestarian adalah: Tata ruang dipreservasi (posisi bangsal tertinggi, simetri pada sumbu Filosofis, terbuka ke Alun-alun Utara). Alun-alun Utara sebaiknya direstorasi (ditumbuhi rumput dan pohon beringin sekelilingnya). Selubung dalam dipreservasi dan dirawat rutin (plafon, balok-balok tumpangsari, talang-talang, jendela skylight, tiang-tiang, lantai). Gaya arsitektur dipreservasi (gaya arsitektur JawaEropa) dan disertai perawatan rutin pada seluruh elemennya (alas tiang, tiang-tiang, balok-balok dan ornamen/ dekorasi). Struktur bangunan dipreservasi dan dirawat rutin seluruh elemennya (balok-balok tumpang sari, tiang-tiang, usuk-usuk atap, elemenelemen purus-lubang, elemen penggantung balok).

\section{Ucapan Terima Kasih}

Puji dan syukur saya panjatkan kepada Allah SWT. atas rachmat dan karunia-Nya sehingga makalah ini dapat terselesaikan dengan baik. Sebagai rasa sukur atas 
terselesaikannya makalah ini, maka adalam kesempatan ini saya haturkan rasa terima kasih kepada yang terhormat:

- Direktorat Riset \& Pengabdian Masyarakat - Direktorat Jendral Penguat Riset dan Pengembangan KEMENRISTEKDIKTI, atas kesempatan riset dan pendanaan melalui Program Hibah Bersaing 2016.

- Para reviewer Jurnal RUAS, atas evaluasi yang telah diberikan sehingga makalah ini dapat selesai dengan baik dan layak muat pada Jurnal RUAS.

- Pimpinan LPPM. UNPAR atas dukungan bantuan yang diberikan.

- Pimpinan Fakultas Teknik UNPAR atas dukungan bantuan yang diberikan.

- Pimpinan Kawedanan Hageng Panitra Pura Kraton Yogyakarta atas kesempatan penelitian yang diberikan.

\section{Daftar Pustaka}

Antariksa, 2007. Pelestarian Bangunan Kuno Sebagai Aset Sejarah Budaya Bangsa, Pidato Pengukuhan Jabatan Guru Besar dalam Bidang Ilmu Sejarah dan Pelestarian Arsitektur Pada Fakultas Teknik Universitas Brawijaya.

Capon, DS., 1999. Le Corbusier's Legacy, John Willey \& Sons Ltd, West Sussex.

Endraswara, S., 2010. Falsafah Hidup Jawa, Cakrawala, Yogyakarta.

Feilden, BM., 2003. Conservation of Historic Buildings, Butterworth-Heinemann Ltd., Oxford.

Heryanto 2015, 2015. Mengenal Kraton Ngayogyakarta Hadiningrat, Warna Mediasindo, Yogyakarta.

Koentjaraningrat. 2015. Kebudayaan, Mentalitas dan Pembangunan, PT. Gramedia, Jakarta.

Mangunwijaya, YB., 1981. Pasal-pasal Penghantar Fisika Bangunan, PT.Gramedia, Jakarta.

Moleong, 2010. Metodologi Penelitian Kualitatif, PT. Remaja Rosdakaarya, Bandung.

Orbasli, A., 2008. Architectural Conservation, Blackwell Science Ltd., Oxford.

Schulz, CN., 1997. Intentions in Architecture, The MIT Press, Cambrigde.

Suryono, A., 2015. Aspek Bentuk dan Fungsi Dalam Pelestarian Arsitektur Bangunan Peninggalan Kolonial Belanda Era Politik Etis di Kota Bandung, Disertasi, Bandung.

Suseno, FM., 1988. Etika Jawa, sebuah analisa falsafati tentang kebijaksanaan hidup Jawa, PT. Gramedia, Jakarta.

Undang-undang Republik Indonesia no. 11, 2010. Bangunan Cagar Budaya. 